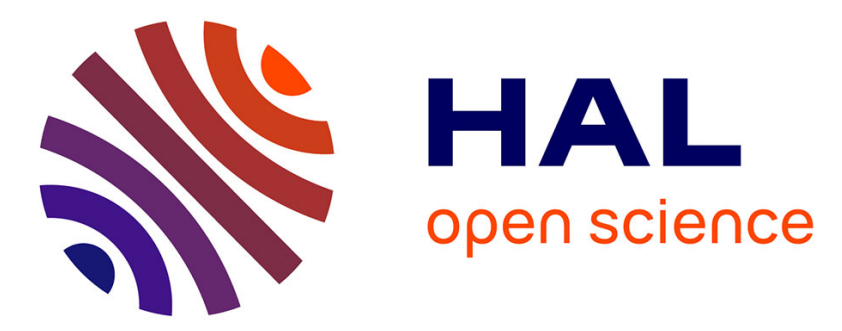

\title{
Safety part design optimisation based on the finite elements method and a genetic algorithm
}

Eric Gildemyn, Philippe Dal Santo, Camille Robert, Alain Potiron, Delphine Saïdane

\section{- To cite this version:}

Eric Gildemyn, Philippe Dal Santo, Camille Robert, Alain Potiron, Delphine Saïdane. Safety part design optimisation based on the finite elements method and a genetic algorithm. International Journal of Design Engineering, 2010, 3 (2), pp.1-19. 10.1504/IJDE.2010.034860 . hal-01281112

\section{HAL Id: hal-01281112 \\ https://hal.science/hal-01281112}

Submitted on 1 Mar 2016

HAL is a multi-disciplinary open access archive for the deposit and dissemination of scientific research documents, whether they are published or not. The documents may come from teaching and research institutions in France or abroad, or from public or private research centers.
L'archive ouverte pluridisciplinaire HAL, est destinée au dépôt et à la diffusion de documents scientifiques de niveau recherche, publiés ou non, émanant des établissements d'enseignement et de recherche français ou étrangers, des laboratoires publics ou privés. 


\title{
Safety part design optimisation based on the finite elements method and a genetic algorithm
}

\section{Eric Gildemyn}

LAMPA - ERT 1055 "ENDOFORM” - Arts et Métiers ParisTech, 2 Boulevard

du Ronceray BP 9352549035 ANGERS, France

\section{Philippe Dal Santo}

LAMPA - ERT 1055 "ENDOFORM” - Arts et Métiers ParisTech, 2 Boulevard du Ronceray BP 9352549035 ANGERS, France

Camille Robert ${ }^{*}$

LAMPA - ERT 1055 “ENDOFORM” - Arts et Métiers ParisTech, 2 Boulevard

du Ronceray BP 9352549035 ANGERS, France

*Corresponding author: camille.robert@angers.ensam.fr

\section{Alain Potiron}

LAMPA - ERT 1055 “ENDOFORM” - Arts et Métiers ParisTech, 2 Boulevard du Ronceray BP 9352549035 ANGERS, France

\section{Delphine Saïdane}

DEVILLE S.A., Zone industrielle de Beauregard, 49150 BAUGE, France

\begin{abstract}
This paper deals with a numerical approach for improving the mechanical properties of a safety belt anchor by optimizing its shape and the manufacturing process by using a multi-objective genetic algorithm (NSGA-2). This kind of automotive component is typically manufactured in three stages: blanking, rounding of the edges by punching and finally bending $\left(90^{\circ}\right)$. This study focuses only on the rounding and bending processes. The numerical model is linked to the genetic algorithm (GA) in order to optimize the shape of the part and the process parameters. This is implemented by using ABAQUS ${ }^{\odot}$ script files developed in the Python programming language and CATIA ${ }^{\odot}$ script files in VBScript. The algorithm modifies the part's design parameters in the CAD system, imports the model in STEP format into ABAQUS CAE and starts the Finite Elements Analysis (FEA) automatically. The material behaviour is modelled using a specific Lemaitre material damage formulation implemented in ABAQUS $^{\odot}$ via a FORTRAN user subroutine. The influence of two process parameters (the die radius and the rounding punch radius) and five shape parameters on the component behaviour is investigated. The search for the optimum component design depends on three objective functions which are (i) the material damage state at the end of the forming process, (ii) the von Mises stress field and (iii) the maximum von Mises stress in the folded zone. A global optimisation is finally performed in order to improve the ultimate unbending load and the volume of the safety part. This work has two major areas of innovation: (a) the improvement of the genetic algorithm NSGA-2; and (b) the development of an integrated numerical procedure including "Computer aided design" and "mechanical finite element simulation" controlled by the genetic algorithm.
\end{abstract}

Keywords: Optimization; Genetic Algorithms (GA); Finite Elements Method; Material Damage; Neural Networks. 
Biographical note: Alain Potiron is professor and Philippe Dal Santo is Professor assistant at "Arts et Métiers ParisTech". Their educational fields are Mechanics and Mechanical engineering. Their research areas are computational mechanics, simulation of forming processes (bending, shearing, deep drawing, superplastic forming), optimisation. Eric Gildemyn is a research engineer in mechanical structures, he graduated, in 2007, from Arts et Métier ParisTech with a PhD on the optimisation of safety components for automotive. Camille Robert has graduated his PHD, in December 2009, on the numerical simulation and optimisation of incremental forming process. Delphine Saïdane is a research engineer from the DEVILLE Company which is the manufacturer of the optimised safety components

\section{Introduction}

This paper focuses on the design and optimisation of a safety-belt anchors. As is the case for all automotive security components, safety-belt anchors must be designed in accordance to national and international standards. The safety belt anchor studied in this paper is manufactured from High Strength Low Alloy steel (HSLA S500MC). The optimisation of the component form and the manufacturing process is carried out by coupling finite element calculations with a modified version of the genetic algorithm NSGA-2, in order to undertake a multi-objective optimization. The aim of the optimization is to create a uniform stress field in the areas of highest stress and to minimize the maximum values of the von Mises stress and the material damage in order to reduce the risk of component failure. This is obtained by modifying the values of five shape parameters and two process parameters.

\section{Description of the manufacturing process}

Lower seat-belt anchors are manufactured from rolled steel strips which are subjected to several sequential forming and shearing operations. The first operation is blanking of the bolt holes and the oblong holes. This is followed by a rounding operation whereby the edges of the oblong holes are rounded by punching. Successive blanking and bending operations of the part shape complete the manufacture of an anchor (Mkaddem and Potiron, 2004; Bahloul et al., 2004). The forming steps are schematically presented in figure 1 below.

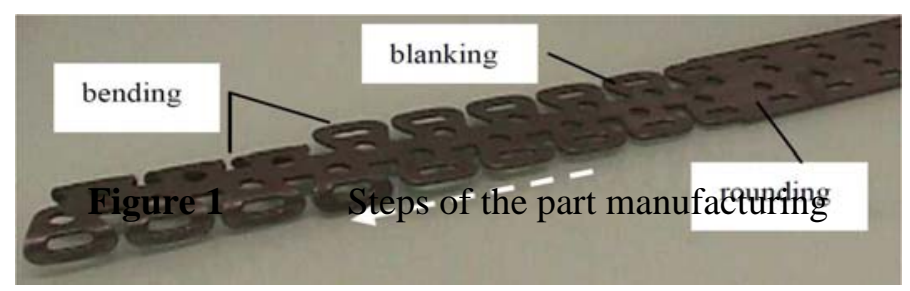




\section{Material behaviour. Elastoplastic model coupled with material damage}

The sheet-metal steel was the High Strength Low Alloyed steel S500MC. The elastic properties are obtained from tensile tests performed on specimen drawn from the steel strip by blanking in the rolling direction (longitudinal). Experiments were carried out on an electro-hydraulic Instron machine. The Young modulus is $218.3 \mathrm{GPa}$, and the Poisson's ration is 0.28 . The kinematic hardening of the material takes place with a backstress $\mathbf{X}$ evoling linearly with the plastic strain tensor:

$$
\mathbf{X}=0.1 \varepsilon^{\mathrm{pl}} \quad \mathrm{MPa}
$$

The isotropic hardening is modelled with the Ludwick law:

$$
\sigma=\sigma_{e}+800\left(\underline{\varepsilon}^{p l}\right)^{0.745} M P a
$$

The Lemaître's material damage law has been experimentally determined by successive loading-unloading sequence:

$$
D=0.55 \underline{\varepsilon}^{p l}
$$

\section{$4 \quad$ General purpose of the study}

\subsection{Industrial problem}

The problem is to predict numerically the mechanical behaviour of the safety component shown in figure 2 taking into account the forming process and to optimise its shape in order to reduce its mass.

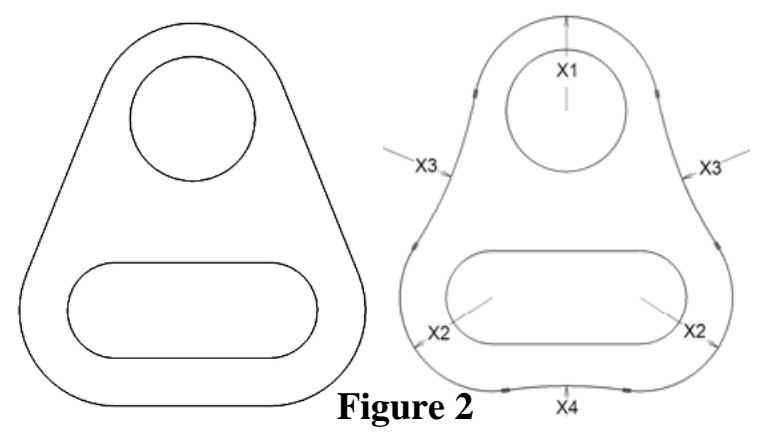

(a) The existing safety belt anchor

(b) Parametric model of the component before bending. 


\subsection{Genetic Algorithms (GA) used to optimise the component}

In this study several algorithms have been tested. Three of them are issued from the KanGAL laboratory in Kânpur and have been developed by Professor K. Deb and co-workers (Deb et al., 2000, IITK, 2009).

The first algorithm uses a basic approach which only allows the optimisation of a single objective function and does not use an "elitist procedure" in which only the best individual are kept in their original configuration without any crossing operation.

The second algorithm investigated is a well known multi-objective algorithm: NSGA (Non-dominated Sorting Genetic Algorithm) and was developed by K. Deb et al. in 1998. As per the previous algorithm, NSGA does not use an elitist system.

The third KanGAL algorithm used in this study is an evolution of NSGA and is referred to as NSGA-2. It allows multi-objective optimisation using an elitist procedure. The version used in this work dates from 2005. This algorithm has been used and tested by many authors (Ferringer and Spencer, 2006; Agarwal and Gupka, 2008).

\subsection{Modification of the NSGA-2 source code for this application}

The NSGA-2 algorithm has been modified to match the objectives of the study and to increase its flexibility. Four modifications have been implemented.

The first allows the use of discrete variables by introducing an array containing the specific values of the discrete parameters. When the NSGA-2 algorithm determines a new "random" parameter value for discrete parameters, the closest discrete value as previously defined is chosen.

Secondly, the algorithm has been modified so that it does not recalculate individuals that already exist. This modification reduces the computing time compared to the original algorithm.

The third modification incorporates the possibility of restarting the algorithm from a break point due to an unexpected or scheduled stop. The algorithm can also restart with a larger number of generations in view of increasing the result accuracy.

The aim of the final modification is to allow the algorithm to be started with a certain number of predefined individuals in the first generation. This allows the algorithm to account for individuals corresponding to existing industrial components, in the first generation.

\subsection{Definition of the problem}

\subsubsection{Objective functions}

In terms of the bending process investigated here, it has been found in a previous study by Bahloul and al., 2005b, 2006b, that the critical area is located around the oblong hole (Figure 3). In order to evaluate the influence of the material damage 
(Lemaitre and Chaboche, 1988) and stress fields on the mechanical behaviour of the component, three dimensionless objective functions have been defined for each individual $i$. These are the maximum material damage value, the relative values of the maximum von Mises stress $\sigma_{v M}^{r e l, i}$ and its maximum standard deviation noted $\delta_{v M}^{r e l, i}$ (The relative standard deviation was examined in order to improve the homogeneity of the stress field in the critical area). They are mathematically written as:

$$
\delta_{v M}^{r e l, i}=\frac{\delta_{s t d}^{i}-\delta_{s t d}^{\min }}{\delta_{v M}^{\max }-\delta_{s t d}^{\min }} \quad ; \sigma_{v M}^{r e l, i}=\begin{aligned}
& \sigma_{v M}^{i}-\sigma_{v M}^{\min } \\
& \sigma_{v M}^{\max }=\sigma_{v M}^{\min }
\end{aligned} ; D^{r e l, i}=\begin{gathered}
D^{i}-D^{\min } \\
D^{\max }-D^{\min }
\end{gathered}
$$

In (3a to 3c), ()$^{\max }$ and ( $)^{\min }$ stands for the maximum values of $D, \sigma_{v M}$ and $\delta_{v M}$ in a generation and $\theta^{i}$ is the value of the current individual. These normalized definitions of the functions assure that they will range in the same interval [0 1].

Figure 3
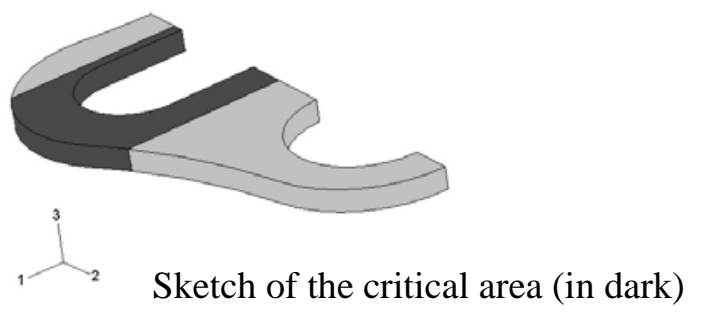

High values of material damage and the von Mises stress can lead to crack initiation or rupture in the folded area. It is therefore of great importance to reduce as much as possible the maximum values of these two quantities.

\subsubsection{Design of the safety-belt anchor}

As the original design of the safety belt anchor is symmetrical only one half of the component is modelled in order to reducing the computation time needed for the simulation of the manufacturing process. The geometry of the half-part is generated in STEP format by means of a macro file for CATIA V5 ${ }^{\odot}$ (CATIA, 2009), written in the VBScript programming language. Included in this macro are geometrical parameters, the values of which may be changed during the optimization, via modification of the original macro file. The four geometrical parameters (X1-X4) defining the component shape are shown in Figure 2. These parameters are the radii of the arcs delimiting the external boundary of the part. Each arc is tangential to its neighbouring arcs. The choice of such a shape avoids introducing stress concentrations due to sharp angles. The fifth parameter (X5) is the thickness $t$ of the part. (X6) and (X7), the sixth and seventh parameters, concern the manufacturing process. They are respectively the bending die radius and the rounding-punch radius. The parameters X3 and X4 can be directed inwards to produce concave shapes or they can be directed outward for convex 
shapes. In this study, the curvatures $1 / \mathrm{X} 3$ and $1 / \mathrm{X} 4$ are considered as being positive if they are directed inwards and negative if they are directed outwards. Resulting from this choice, nine generic component shape families can be obtained. These are sketched in Figure 4.

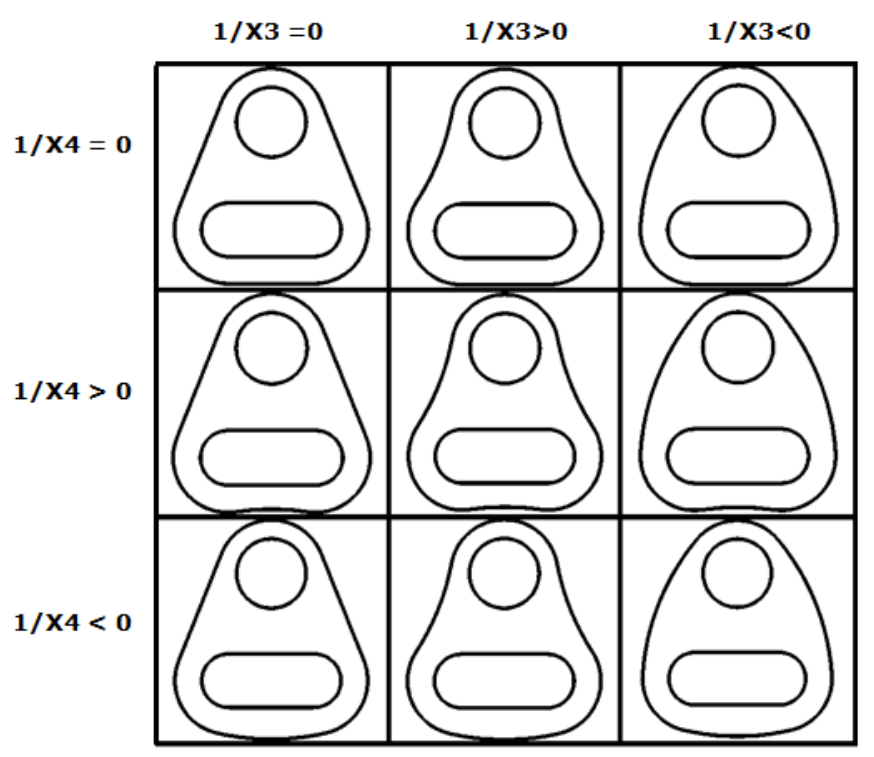

Figure 4 Generic shapes families

The bolt hole for attaching the belt-anchor to the chassis and the oblong hole for the seat belt attachment have fixed dimensions and positions as they are imposed by the automotive manufacturer. Once it is generated, the half-part geometry is saved in STEP format which insures good transferability from the CAD program CATIA ${ }^{\circledR}$ to the CAE pre-processor of ABAQUS ${ }^{\circledR}$ (ABAQUS, 2001).

\section{$5 \quad$ Numerical modelling}

\section{$5.1 \quad$ Numerical model}

The numerical model of the edge rounding punches is generated in the same way as that of the safety-belt anchor, by creating a dedicated macro file within CATIA $^{\odot}$ and saving the geometry in STEP format. The finite elements used for modelling the component are eight node bricks with reduced integration, C3D8R in ABAQUS. The element size is chosen in the range [0.8mm-1.2mm], depending on the part thickness. The manufacturing tools, i.e. the punch and die, are modelled as rigid bodies. The rounding punch is modelled as a discrete rigid body and analytical rigid bodies are used for the bending tools: die, blank-holder and punch. The contacts between the component, the blank-holder and the die are governed by Coulomb's law with a friction coefficient $\mu=0.1$ while the others 
contacts are assumed to be frictionless. These values have been determined in previous works (Bahloul et al., 2004, Mkadem et al. 2004).

\subsection{Punch rounding process modelling}

The rounding operation is done by punching the edges of the oblong hole in view of: (i) increasing the yield stress in that area by work hardening and (ii) to avoid cutting of the seat belt by the burred edge created by the blanking process. Therefore, this operation takes place just after the blanking process. Figure 5a illustrates the virtual components used in the rounding operation (component and tools) as they are modelled in the F.E code.
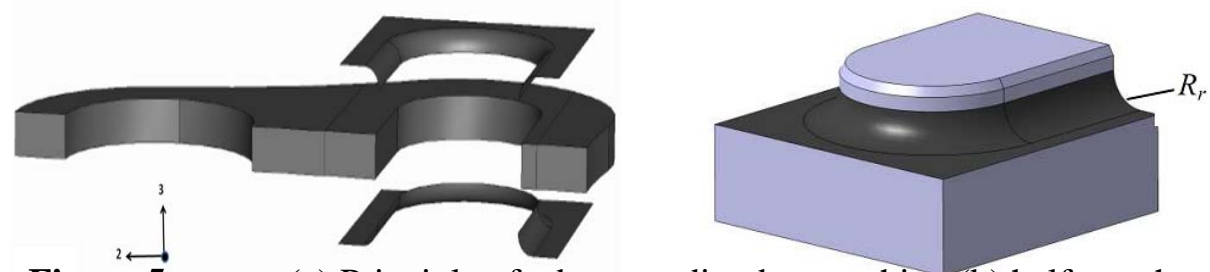

Figure 5

(a) Principle of edge rounding by punching (b) half punch

It can be seen in the above figure that only the surfaces coming into contact with the part are modelled. The actual punch with a radius $R_{r}$ equal to $1.75 \mathrm{~mm}$, is used for the edge rounding operation as shown in Figure 5b. It is assumed that this radius will have an important effect on the mechanical behaviour of the final component. Therefore it is varied in the optimisation process. Therefore in place of $R_{r}$ a dimensionless parameter $\mathrm{X} 7$ is used for the analysis, defined by the following ratio: $X 7=R_{r} / t$. The half-punches shown in figure $5 b$ as surfaces are shown in a darker colour in figure $5 \mathrm{~b}$. The influence of the rounding operation on the final part behaviour will appear at the end of the wiping die bending operation by modifying the final stress and material damage fields. The best component shape is that which minimizes the residual stress and damage fields after tools removal, it is therefore necessary to account for the die radius effect on the final mechanical state of the safety-belt anchor.

\subsection{Bending process simulation}

The relative positions of tools and component at the beginning of the simulation are illustrated in Figure 6. The influence of the bending parameters shown in the figure, (i.e. the clearance $c$ between the tools, the die and punch radii $R_{d}$ and $R_{p}$ ) on the final part behaviour when it is loaded was investigated in (Bahloul et al., 2005a, 2006a). In the present study, the punch radius and the clearance are constants, respectively equal to the part thickness $t$ and $0.1 \times t$ (Mkadem and Potiron, 2004; Ferringer and Spencer, 2006). Consequently, the only bending process parameter which is optimised in this work is the die radius $R_{d}$. This parameter is related to the thickness of the part by means of the dimensionless 
parameter X6 defined by the ratio: X6 $=\mathrm{R}_{\mathrm{d}} / \mathrm{t}$. Because cracks might appear at the end of the bending operation due to severe stretching, the value of this parameter is often greater than 0.5 .
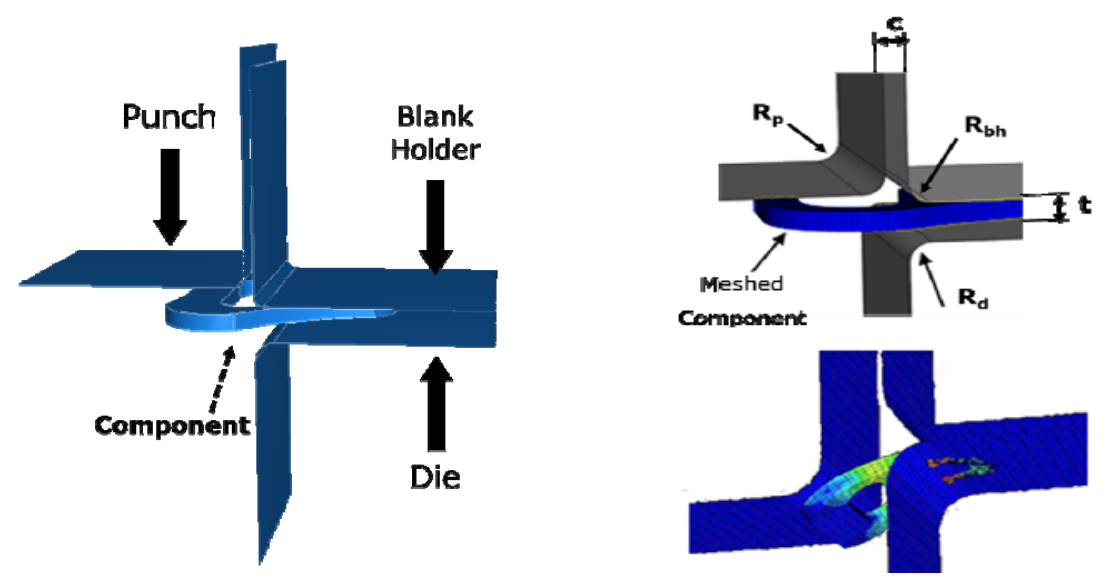

Figure 6 Simulation of the bending process

\subsection{Unbending Simulation}

The unbending operation detailed further (chapter 7) is integrated in the numerical modelling to simulate the part behaviour in case of a sudden and important load applied by the belt to the anchor and thus to test its resistance. The unbending operation uses discrete rigid part simulating the action of the seat belt. This operation allows the calculation of the ultimate unbending load. Figure 7 shows the component at the end of the unbending step.
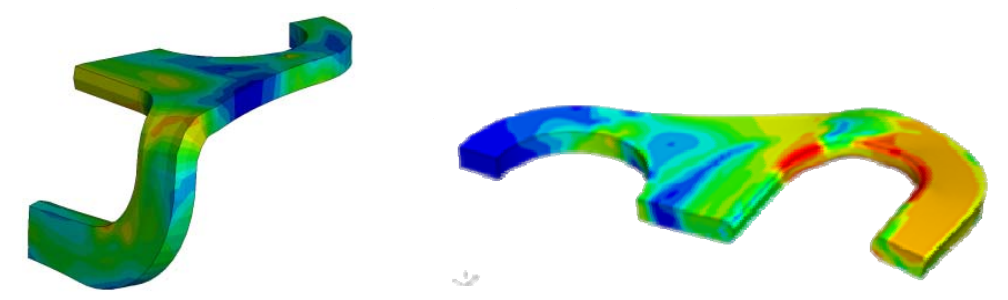

$\begin{array}{ll}\text { Figure } 7 & \text { The part before and after the unbending step }\end{array}$

\section{General optimisation}

\subsection{Optimisation loop}

As already discussed the well-known genetic algorithm NSGA-2 has been used in this study. The original program developed by the KanGal laboratory in Kanpur has been modified in order to use discrete variables and to check if an 
individual has already been used in order to assure that individuals are not repeated. The parameters X3 to X7 are defined as discrete variables and only X1 and $\mathrm{X} 2$ as used as real variables, in order to limit the problem size and to take account of the different families of shapes and sheet-metal supplying.

The optimisation loop, including the CAD modelling, the numerical simulation on ABAQUS governed by the NSGA-2 algorithm is described on the Figure 8 below.

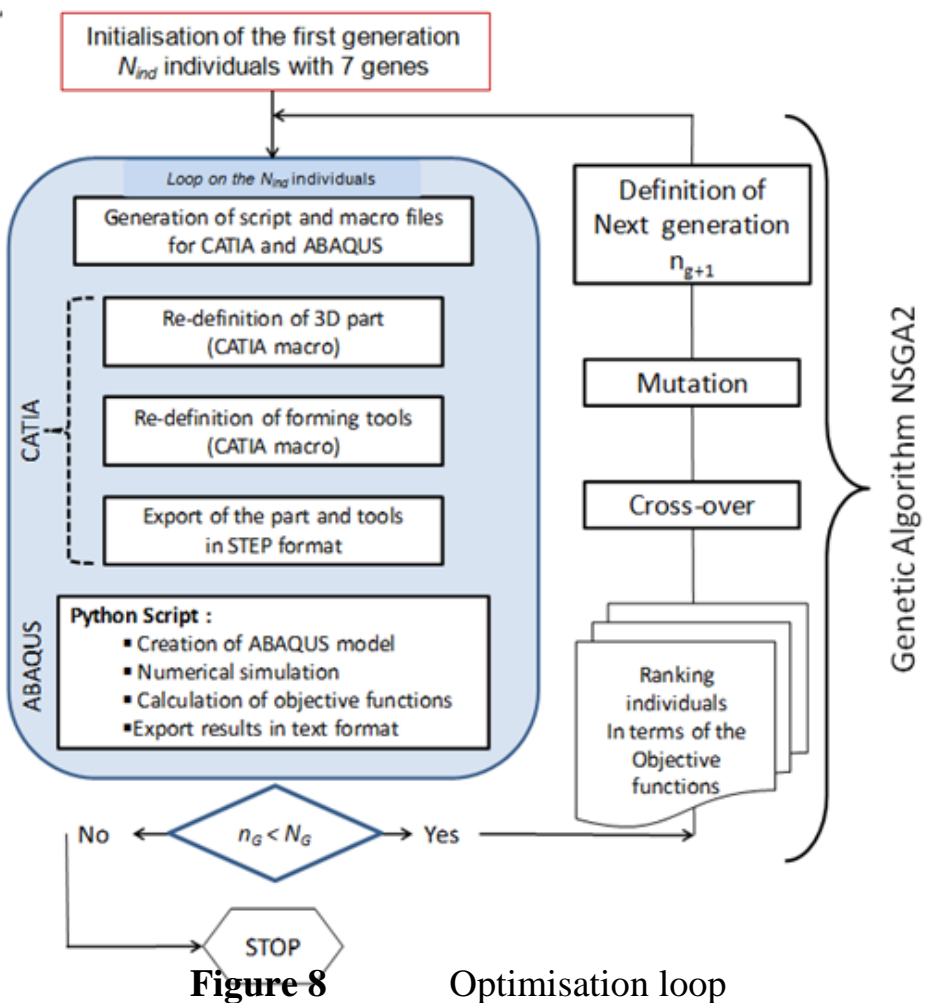

\subsection{Controlling the genetic algorithm}

The control parameters for the optimisation process using NSGA-2, must carefully be selected as their choice will affect the convergence of the simulation loop. In this work two runs were compared in order to characterise the influence of the number of individuals with respect to the number of generations. The first run was carried out with 30 generations including 20 individuals in each generation A second run used 10 generations and 60 individuals so that in both cases, 600 individuals were tested. They are respectively denoted Gen30_Ind20 and Gen10_Ind60 in the figures. Figure 9 summarises three sets of results corresponding to the last generations for both runs $(30 \times 20$ and $10 \times 60)$ and the 
first generation of the $30 \times 20$ run. All values are relative values corresponding to the normalized objective functions defined in section 4.3.1, equations (3a,b,c).

The performance of an individual depends on the two material characteristics stress and damage and also on the part design which influences the stress distribution inside the critical area (Figure 3). Consequently, three graphs are constructed. In the first and second ones (a,b) $\delta_{v M \max }$ and $D_{\max }$ are plotted against $\sigma_{v M \max }$ and in the third one, $\delta_{v \max }$ is plotted as a function of $D_{\max }$. So, it is possible to determine the "best" individual lying on the Pareto front, matching a prescribed ratio between two functions.

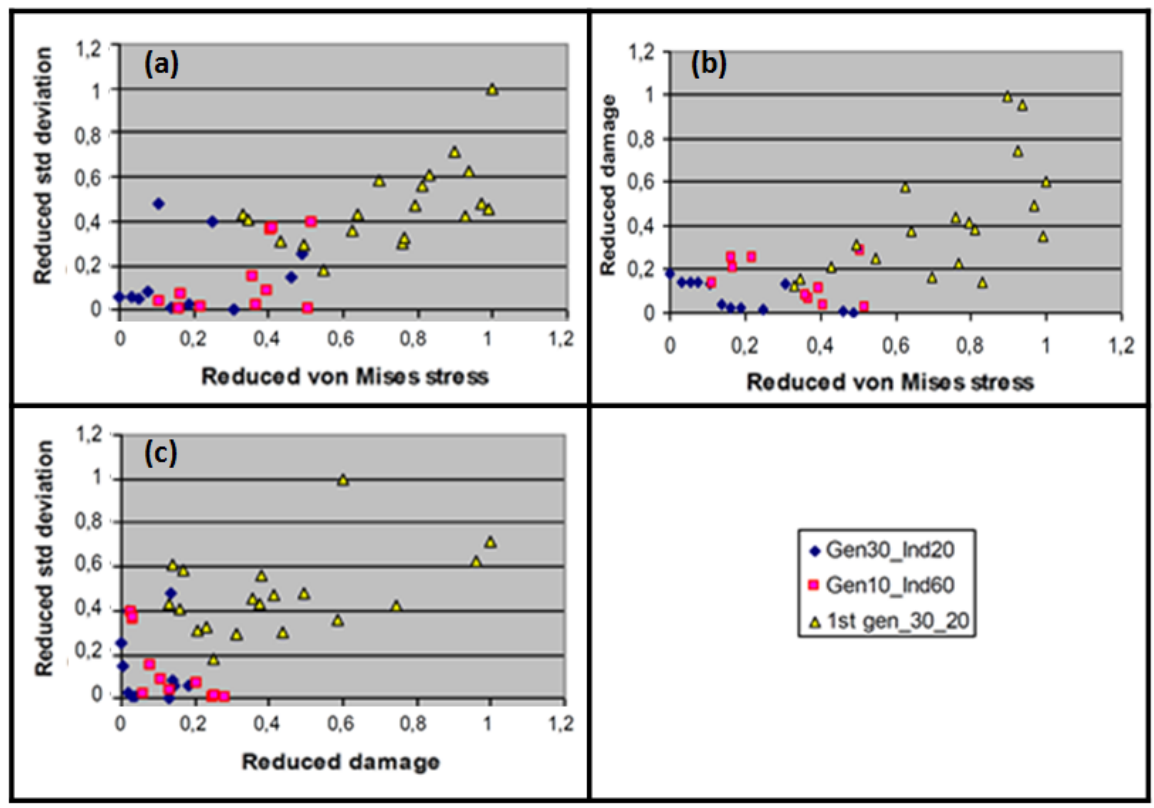

Figure 9 3D Pareto front projections including the first generation

The best individuals must minimize the different values, as per equation (4). It can be seen that the individuals minimising the different relative values belong mainly to the $30 \times 20$ run even though the initial population lies far from the best choice. The second run $10 \times 60$ does not give better results. It is therefore concluded that, for a given number of evaluations the genetic algorithm works best with a large number of generations rather than a large number of individuals per generation. In this work, the optimisation includes a finite element calculation for each individual in each generation. Hence the computational time is very long (greater than 2 hours per individual using an Intel bi-processor $2 \mathrm{kHz}$ with 4 Go RAM). Therefore, in view of limiting the CPU time to a reasonable length, the optimisation is limited to runs with 15 generations of 20 individuals per generation. The performances of the offsets of the $15^{\text {th }}$ generation are shown in Figure 10. In each case it is seen that there are some individuals lying on the different fronts, indicating that the performances of the run Gen15_Ind 20 are satisfactory and it is supposed that the same conclusions should be done in others 
simulations. So, in the following investigations the GA will run with 15 generations of 20 individuals.

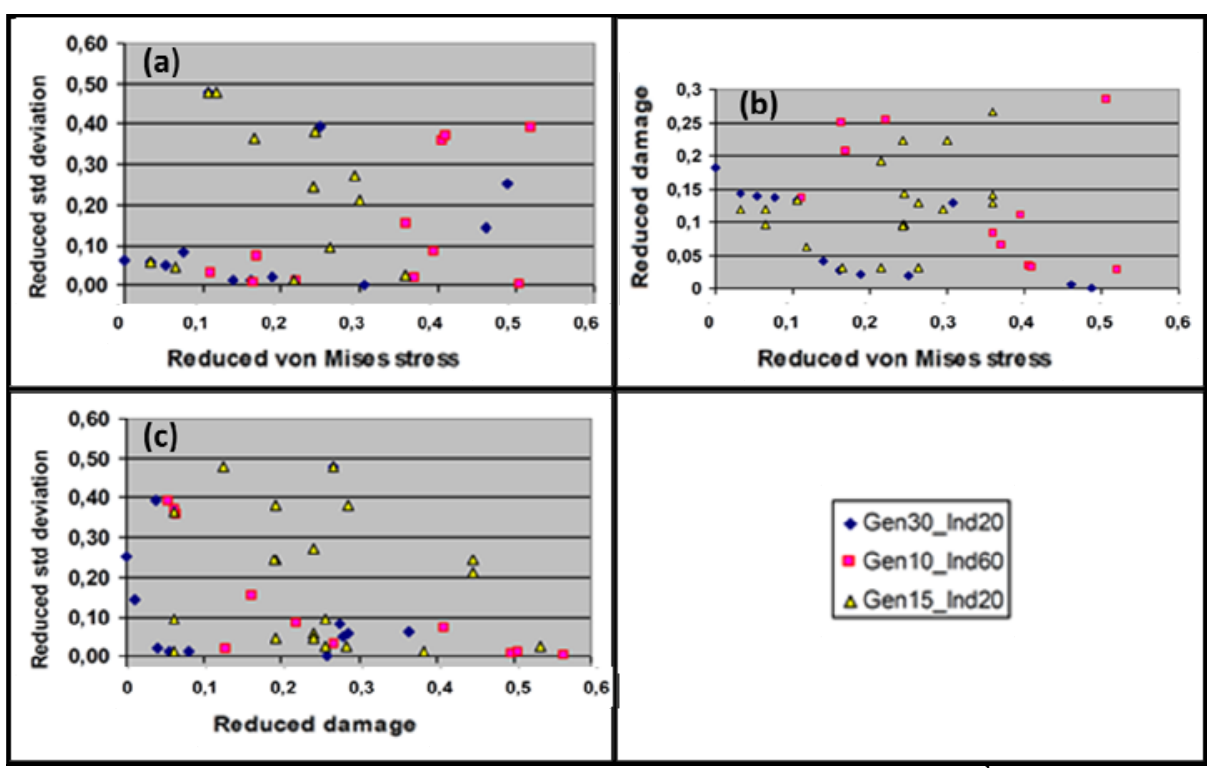

Figure 10 3D Pareto front projections including the $15^{\text {th }}$ generation

\section{$7 \quad$ Simulation of the part unbending operation}

The unbending of the component is a quasi-static operation carried out on a tensile machine and is done to characterise the resistance of the component. In a real situation the mechanical loading on a seat-belt anchor is a shock load applied by the seat-belt in the case of an accident. In real dynamic experiments, tests are carried out on a Charpy pendulum machine. The anchor is clamped on the machine with a bolt and the belt which is attached to the part through the oblong hole, is connected to the pendulum. The objective here is not to reproduce the dynamic behaviour of the component, but to determine the maximum load needed to unbend or straighten the anchor. Tests performed on anchors, at different strain rates have shown that the relative error between dynamic and static unbending maximum loads is approximately 4\% (Bahloul, 2005). These results indicate that the quasi-static maximum unbending load is a sufficiently accurate indicator of the component resistance to be used in the optimisation strategy. Furthermore, in the numerical simulations the belt is modelled by a discrete rigid part whose displacement is imposed at a reference point. Such a representation avoids accounting for the complex material behaviour of a real woven security belt. The load values exerted by the belt on the part are recovered at the reference point. The element type used to model the seat-belt is 4 node rigid elements (R3D4 in ABAQUS). The belt is moved $22.6 \mathrm{~mm}$ at an angle of $45^{\circ}$ to the XY plane insuring that the anchor is completely unbent. In the unbending step, the clamping conditions are replaced by built-up condition 
around the bolt hole. The Figure 11(a) below shows the positions of the fictitious belt and the part at the beginning of the unbending operation.
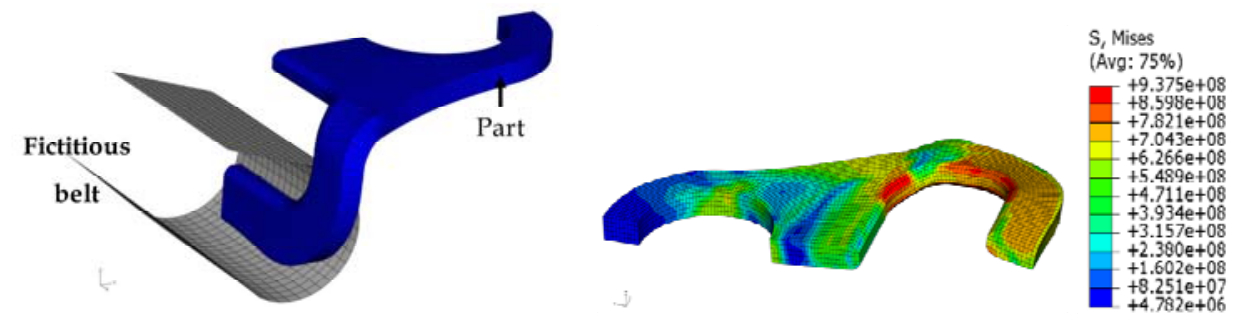

Figure 11

(a) Initial position of part and belt

(b) Von Mises stress field of an unbent component

The von Mises stress field of an unbent component is illustrated in Figure 11(b). It shows that the maximum values occur around the oblong hole and correspond to the areas in which the risk of failure is the highest. This also post explains the choice of the critical area position in Figure 3. At the end of this operation (but before releasing the imposed displacement) the maximum load, stress and damage fields are determined and recorded in a file in view of post-processing operations.

\section{Simulation of the successive operations}

The complete sequence of the components life begins with its blanking and stops at the time of its unbending resulting from a shock transmitted by the security belt in case of an accident (Gildemyn, 2008). The blanking operation which has been extensively investigated in the past by Hambli and Potiron, 2000, and Hambli et al. 2003, using specimens similar to the safety-belt anchor was not taken into account in this work. The aforementioned authors have demonstrated that the overall behaviour of the part is not affected by the very local effects of material shearing, provided that optimum shapes of the punch and the die edges are used and that an optimum clearance between the tools is chosen (about 10\% of the sheet-metal thickness). Therefore, the simulation of the different stages of the component manufacturing process begins with the rounding of the edges of the oblong hole by punching. The simulation of the successive steps is briefly described in Table 1. It should be noted that the different figures show the von Mises stress field.

\begin{tabular}{l|l}
\hline a- Edge rounding by punching & $\begin{array}{l}\text { The two punches are moved into place on each side } \\
\text { of the oblong hole (Figure 5) }\end{array}$ \\
\hline b- Edge rounding by punching & $\begin{array}{l}\text { Realisation of the punching of the two faces of the } \\
\text { hole }\end{array}$ \\
\hline c- Part bending & $\begin{array}{l}\text { After rounding, the punches are removed from the } \\
\text { operating zone and the component is kept in place }\end{array}$ \\
\hline d- Part bending & $\begin{array}{l}\text { The part is bent between a bending punch and a die } \\
\text { with calibrated clearances (Figure 6) }\end{array}$ \\
\hline e- Part unbending & The bending tools are removed from the operating \\
\hline
\end{tabular}




\begin{tabular}{c|l}
\hline & zone. The fictitious belt is positioned (Figure 11) \\
\hline f- Part unbending & The part is completely straightened by the belt \\
\hline \multicolumn{2}{c}{ Table 1 }
\end{tabular}

\section{$9 \quad$ Optimisation of the whole process}

\subsection{Global optimisation loop}

When using NSGA-2, the first step is to define the initial generation composed of an optimum number $\mathrm{N}_{\text {ind }}$ of individuals with respect to certain criteria like computing time, accuracy of the results and so on. In section 5 it was concluded that 20 was a sufficient number of individuals per generation. Each individual will be composed of seven genes which are the parameters defined in section 4.3.2 and each population of individuals evolves according to some criterion of selection in the presence of variation-inducing operators such as mutation and crossover. Generally a fitness function is used to evaluate individuals and the best ones will be chosen to remain in the next generation. In this study, there are two objective functions which will be evaluated that is the volume of the security part and the maximum unbending load. So for each set of seven parameters there is a set of two outputs, which are the values of the objectives functions. Once they are computed for all individuals in the first generation, the G.A evaluates the individuals and ranks them to determine the $\mathrm{N}_{\text {ind }}$ best ones. Then a probability is attributed to each remaining individual for mutation and cross-over steps at the end of which a larger population is obtained. The values of the objective functions are computed for the whole set of the offsets that next are ranked. The best 20 individuals are kept to create the second generation in order to have the same number of individuals $\mathrm{N}_{\text {ind }}$ as in the initial generation. The individuals defining the second generation are then submitted to mutation, cross-over and selection operations in the same way. This is repeated until a given number $\mathrm{n}_{\mathrm{G}}$ of generations is reached, at which point the optimisation is stopped.

Table 2 summarises the values of the GA parameters resulting in convergence of the algorithm.

\begin{tabular}{l|l}
\hline Number of generations $N_{G}$ & 15 \\
\hline Number of individuals by generation $\mathrm{N}_{\text {ind }}$ & 20 \\
Crossover probability & 0.9 \\
Mutation probability & 0.2 \\
Distribution index for crossover & 20 \\
Distribution index for mutation & 50 \\
\hline
\end{tabular}

Table 2

NSGA-2 parameters choice

In order to fully automate the process, a control algorithm was developed. This involved certain modifications to NSGA-2. The control algorithm automatically rewrites the scripts files for CATIA and ABAQUS with the parameters corresponding to each individual, and then the finite element simulation is automatically performed. The optimisation loop is sketched in Figure 12. 


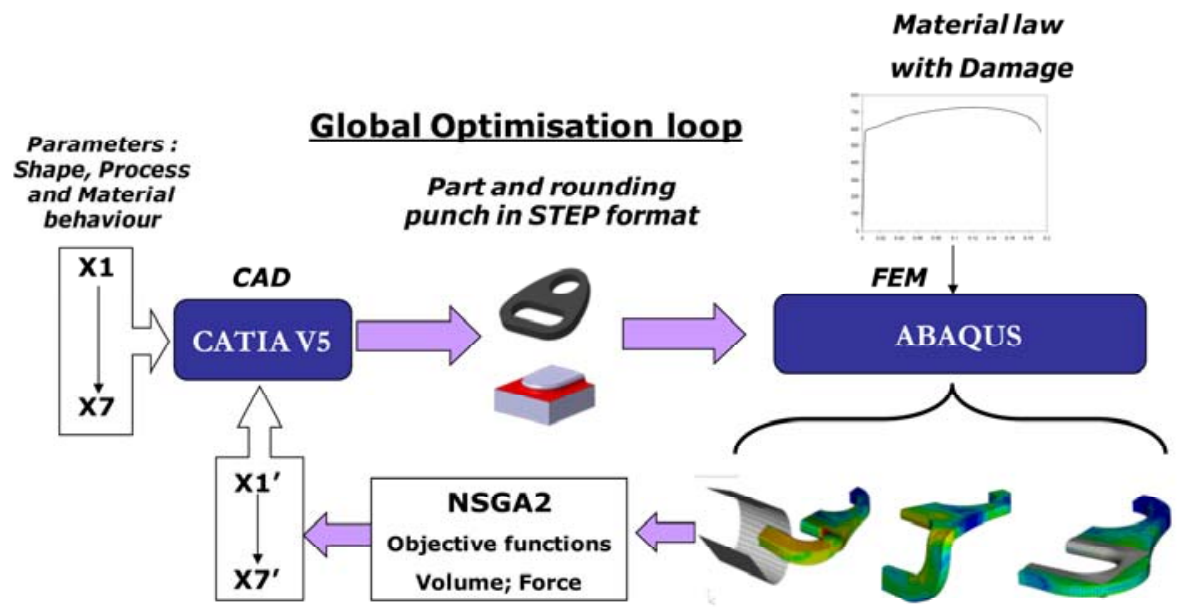

Figure 12 Algorithmic loop

\subsection{Optimisation problem}

The aim of the study is to determine the best safety belt anchor. That is the component which minimises the volume of material used and maximises the strength of the component. The shape of the part and the manufacturing process are the two factors influencing the choice of an optimum solution. The corresponding component optimisation parameters $\mathrm{X} 1 \ldots \mathrm{X} 5$ were defined in section 3 and the two process parameters $\mathrm{X} 6-\mathrm{X} 7$ are discussed in section 4 . The feasible domain is defined by the boundary imposed by the parameters bounds given in Table 3. Due to certain process and design constraints, some parameters can vary continuously and others can take only discrete values. For example, the sheet-metal thickness X5 is a discrete parameter so that standard sheet thickness can be used. In the following X5 is $2 \mathrm{~mm}$ to $4 \mathrm{~mm}$ with steps of $0.5 \mathrm{~mm}$. The signs "+ " or "- " are related to concave or convex component edges (Figure 4).

\begin{tabular}{c|ccc}
\hline Parameters & Minimum Value $(\mathrm{mm})$ & Maximum Value $(\mathrm{mm})$ & Variable type \\
\hline X1 & 8.0 & 12.0 & Real \\
X2 & 8.0 & 12.0 & Real \\
X3 & -65 & +65 & Discrete \\
X4 & -65 & +65 & Discrete \\
X5 & 2.0 & 4.0 & Discrete \\
X6 & 1.0 & 2.0 & Discrete \\
X7 & 1.5 & 2.0 & Discrete \\
\hline
\end{tabular}

Table $3 \quad$ Bounds of optimisation variables 
During the study it was found that the inverse unbending load values were better for the analysis of the component behaviour and consequently the unconstrained optimisation problem is given by:

- $\quad$ Minimise PartVolume $=f_{l}\left(X_{i}\right)$

- $\quad$ Minimise (UnbendingLoad) ${ }^{-1}=f_{2}\left(X_{i}\right)$

With the variables $X_{i}$ defined in Table 3 .

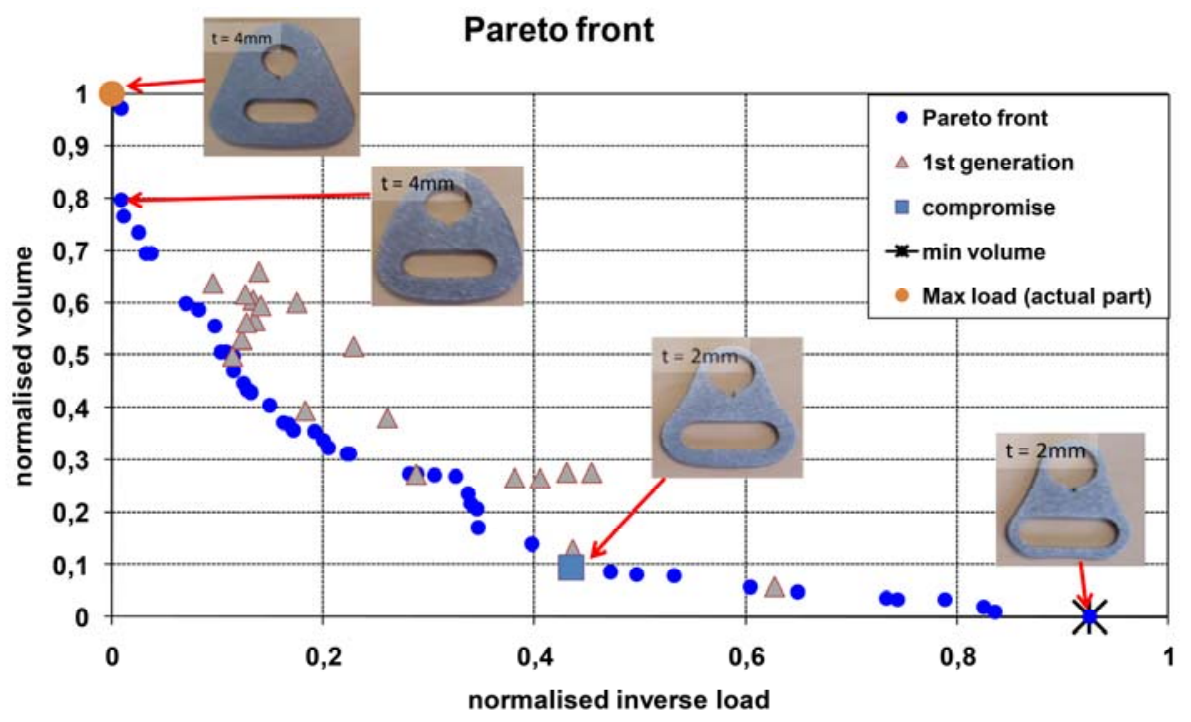

Figure 13 Pareto front Volume vs Normalised inverse load

On the Figure 13, the positions of the best individuals from all of the generations and those of the first generation are shown. In view of improving the design, the existing component is also shown on the figure $(\bullet)$. It can be noted that the volume and unbending load for this individual is the highest. A component as per the one located slightly below the existing component is lighter and has approximately the same resistance. Inversely the component with the minimum volume $(*)$ is the weakest. Therefore, by using both technical and economical criteria it is possible to choose a component exhibiting the best compromise price and security. The individual represented by ( $\bullet$ ) on the figure, corresponds to the fact that the gradient $d V / d\left(F^{-1}\right)$ of the volume with respect to the inverse load is quite zero. Hence, a slight decrease in volume induces a large decrease of the part resistance.

Table 4 below summarises the different parameters values associated with certain individuals shown in Figure 2. The simulations results for the original part give a Force value of approximately $10 \mathrm{kN}$ for a volume $50 \%$ greater than the $\mathrm{F}_{\max }$ configuration. 


\begin{tabular}{l|ccccccccc}
\hline Part_parameters & $\begin{array}{c}X 1 \\
(\mathrm{~mm})\end{array}$ & $\begin{array}{c}X 2 \\
(\mathrm{~mm})\end{array}$ & $\begin{array}{c}X 3 \\
(\mathrm{~mm})\end{array}$ & $\begin{array}{c}X 4 \\
(\mathrm{~mm})\end{array}$ & $\begin{array}{c}X 5 \\
(\mathrm{~mm})\end{array}$ & $\begin{array}{c}X 6 \\
(\mathrm{~mm})\end{array}$ & $\begin{array}{c}X 7 \\
(\mathrm{~mm})\end{array}$ & $\begin{array}{c}\text { Volume } \\
\left(\mathrm{m}^{3}\right)\end{array}$ & $\begin{array}{c}\text { Limit } \\
\text { Load } \\
(\mathrm{N})\end{array}$ \\
\hline 2nd_part & 8.57 & 12 & -65 & -45 & 4 & 1.8 & 2 & $3.37 \mathrm{e}^{-6}$ & 8990 \\
Compromise & 8.52 & 9.81 & 55 & -55 & 2 & 1.6 & 1.6 & $1.2 \mathrm{e}^{-6}$ & 3070 \\
Fmax & 12 & 12 & -65 & -45 & 4 & 1.6 & 2 & $3.99 \mathrm{e}^{-6}$ & 9330 \\
Vmin & 8.45 & 8.05 & 55 & 65 & 2 & 1.6 & 1.9 & $0.9 \mathrm{e}^{-6}$ & 1640 \\
\hline
\end{tabular}

Table 4

Parameters values and objective functions

Figure 14 presents the last two columns of Table 4 so that the specific resistance of the component (Newton) is related to its weight (grams). The components are ordered by decreasing unbending load/weight ratio. It can be concluded that the component labelled compromise exhibits the best behaviour of the whole set of parts when the required material volume is accounted for. On the other hand, the original component seems to be the worst of all, therefore justifying the present work.

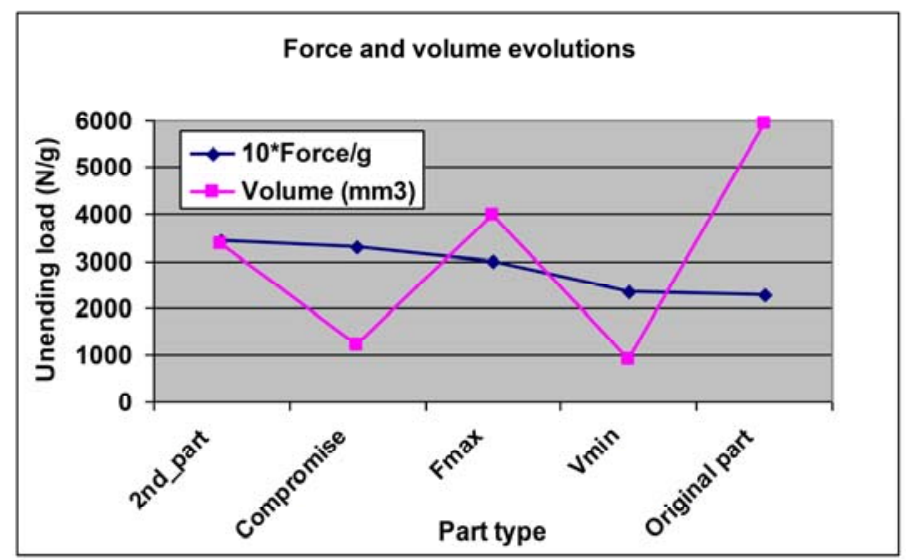

Figure 14

Representations of the relative values of maximum unbending loads and volumes

In view of comparing the ratio of volumes and unbending load, the original component is taken as reference and the corresponding results are reported in Table 5 below.

\begin{tabular}{c|cccc}
\hline Part & 2nd_part & compromise & Fmax & Vmin \\
\hline Volume ratio & 0.5673 & 0.202 & 0.6717 & 0.1515 \\
Force/g ratio & 1.5144 & 1.4524 & 1.3275 & 1.0345 \\
\hline
\end{tabular}

Table $5 \quad$ Relative behaviour of the parts

Once more, it can be observed that the component labelled compromise which has a volume of approximately $20 \%$ of the original part has a ratio N/g of about $45 \%$ higher. The best N/g ratio is found for the $2^{\text {nd }}$-part but the volume ratio is 2.5 times the component compromise. These large differences in component 
material damage'. $4^{\text {th }}$ Eur opean Congress on Comp utational Methods in Applied Sciences and Engineering, Jyväskylä, Finland.

Bahloul, R., (2005) 'Optimisation du procédé de pliage sur presses de pièces en tôles à haute limite d'élasticité'. Ph.D. Thesis, ENSAM, Angers, France, 2005ENAM0031.

Bahloul, R., Dal Santo, P., Potiron, A., (2005a) 'Optimization of process parameters in wiping die bending operation in order to minimise of stresses and Lemaitre's damage'. International conference on material forming ESAFORM 2005, 27-29 April, Cluj-Napoca, Roumania, pp. 159162.

Bahloul, R., Ben Eléchi, S., Dal Santo, Ph., Potiron, A., (2005b) 'Optimisation of the L-bending process: A comparison between Response Surface, Moving Least Squares and Evolution Strategies Methods'. Proceedings of the first invited COS T 526 conference on Automatic Process Optimiza tion i $n$ Materials Technology, May 30-31, Morschach, Switzerland, pp. 120-131.

Bahloul, R., Ben Eléchi, S., Dal Santo, P., Naceur, H., Potiron, A., (2006a) 'Optimization of the bending process by means of response surface and moving least squares method'. Far East Journal of Applied Mathematics, 22(1), pp. 25-54.

Bahloul, R., Mkaddem, A., Dal Santo, Ph., Potiron, A., (2006b) 'Sheet metal bending optimisation using response surface method, numerical simulation and design of experiments. International Journal of Mechanical Sciences', Vol. 48, pp. 991-1003.

CATIA Dassault Systems manual, (2009) http://catiadoc.free.fr/online/CATIA_default.htm.

Deb, K., Agrawal, S., Pratap, A., Meyarivan, T., (2000) 'A fast elitist nondominated sorting genetic algorithm for multi-objective optimisation: NSGA II'. Proceedings of the Parallel Pr oblem Solving from Nature VI Conference, Paris, France, September 16-20, pp. 849-858.

Ferringer, M. P., Spencer, D. B., (2006) 'Satellite constellation design tradeoffs using multiple-objective evolutionary computation'. Journal of Spacecraft and Rockets, 43(6), pp. 1404-1411.

Gildemyn, E., (2008) 'Caractérisation des procédés de fabrication de pièces de sécurité automobile. Optimisation multi-objectifs de la mise en forme'. Ph.D. thesis, Arts et Métiers ParisTech, Angers, France, 2008ENAM0019.

Hambli, R., Potiron, A., (2000) 'Finite element modelling of sheet-metal blanking operations with experimental verification'. Journal of M aterials Processing Technology, Vol. 102, Issues 1-3, pp. 257-265.

Hambli, R., Mkaddem, A., Potiron, A., (2003) 'Damage prediction in L-bending process using FE model'. International Jo urnal of Advanced Manufacturing Technology, Vol.22, No. 1-2, pp. 12-19.

IITK, 2009. http://www.iitk.ac.in/kangal/codes.shtml

Lemaître, J., Chaboche, J.L., (1988) 'Mécanique des Matériaux Solides', Dunod, Paris, ISBN 2040186182.

Mkaddem, A., Potiron, A., (2004) 'Fold zone analysis in wiping die-bending process by using experimental and numerical approaches'. International Journal for Numerical Methods in Engineering. Vol. 61, pp. 303-315. 
material damage'. $4^{\text {th }}$ Eur opean Congress on Comp utational Methods in Applied Sciences and Engineering, Jyväskylä, Finland.

Bahloul, R., (2005) 'Optimisation du procédé de pliage sur presses de pièces en tôles à haute limite d'élasticité'. Ph.D. Thesis, ENSAM, Angers, France, 2005ENAM0031.

Bahloul, R., Dal Santo, P., Potiron, A., (2005a) 'Optimization of process parameters in wiping die bending operation in order to minimise of stresses and Lemaitre's damage'. International conference on material forming ESAFORM 2005, 27-29 April, Cluj-Napoca, Roumania, pp. 159162.

Bahloul, R., Ben Eléchi, S., Dal Santo, Ph., Potiron, A., (2005b) 'Optimisation of the L-bending process: A comparison between Response Surface, Moving Least Squares and Evolution Strategies Methods'. Proceedings of the first invited COS T 526 conference on Automatic Process Optimiza tion i $n$ Materials Technology, May 30-31, Morschach, Switzerland, pp. 120-131.

Bahloul, R., Ben Eléchi, S., Dal Santo, P., Naceur, H., Potiron, A., (2006a) 'Optimization of the bending process by means of response surface and moving least squares method'. Far East Journal of Applied Mathematics, 22(1), pp. 25-54.

Bahloul, R., Mkaddem, A., Dal Santo, Ph., Potiron, A., (2006b) 'Sheet metal bending optimisation using response surface method, numerical simulation and design of experiments. International Journal of Mechanical Sciences', Vol. 48, pp. 991-1003.

CATIA Dassault Systems manual, (2009) http://catiadoc.free.fr/online/CATIA_default.htm.

Deb, K., Agrawal, S., Pratap, A., Meyarivan, T., (2000) 'A fast elitist nondominated sorting genetic algorithm for multi-objective optimisation: NSGA II'. Proceedings of the Parallel Pr oblem Solving from Nature VI Conference, Paris, France, September 16-20, pp. 849-858.

Ferringer, M. P., Spencer, D. B., (2006) 'Satellite constellation design tradeoffs using multiple-objective evolutionary computation'. Journal of Spacecraft and Rockets, 43(6), pp. 1404-1411.

Gildemyn, E., (2008) 'Caractérisation des procédés de fabrication de pièces de sécurité automobile. Optimisation multi-objectifs de la mise en forme'. Ph.D. thesis, Arts et Métiers ParisTech, Angers, France, 2008ENAM0019.

Hambli, R., Potiron, A., (2000) 'Finite element modelling of sheet-metal blanking operations with experimental verification'. Journal of M aterials Processing Technology, Vol. 102, Issues 1-3, pp. 257-265.

Hambli, R., Mkaddem, A., Potiron, A., (2003) 'Damage prediction in L-bending process using FE model'. International Jo urnal of Advanced Manufacturing Technology, Vol.22, No. 1-2, pp. 12-19.

IITK, 2009. http://www.iitk.ac.in/kangal/codes.shtml

Lemaître, J., Chaboche, J.L., (1988) 'Mécanique des Matériaux Solides', Dunod, Paris, ISBN 2040186182.

Mkaddem, A., Potiron, A., (2004) 'Fold zone analysis in wiping die-bending process by using experimental and numerical approaches'. International Journal for Numerical Methods in Engineering. Vol. 61, pp. 303-315. 
Mkaddem, A., Potiron, A., Boude, S., (2004) 'Finite element modelling of unbending tests with damage approach and experimental verification'. Journal of Materials Proc essing Technology, Vol. 152, Issue 2, pp. 246255. 